\title{
DÜBLIN
}

Technological University Dublin

ARROW@TU Dublin

Conference Papers

School of Physics \& Clinical \& Optometric

Science

2009-01-01

\section{Macular Pigment and its Contribution to Spatial Vision}

\author{
James Loughman \\ Technological University Dublin, james.loughman@tudublin.ie \\ Peter Davison \\ Technological University Dublin, Peter.Davison@tudublin.ie \\ Grainne Scanlon \\ Technological University Dublin, grainne.scanlon@tudublin.ie
}

See next page for additional authors

Follow this and additional works at: https://arrow.tudublin.ie/scschphycon

Part of the Medicine and Health Sciences Commons

\section{Recommended Citation}

Akkali, M., Nolan, J., \& Beatty, S., (2009). Macular Pigment and Its Contribution to Spatial Vision. Association for Research in Vision and Ophthalmology Conference Investigative Ophthalmology and Visual Science. doi:10.1111/j.1755-3768.2008.644.x

This Conference Paper is brought to you for free and open access by the School of Physics \& Clinical \& Optometric Science at ARROW@TU Dublin. It has been accepted for inclusion in Conference Papers by an authorized administrator of ARROW@TU Dublin. For more information, please contact arrow.admin@tudublin.ie, aisling.coyne@tudublin.ie,gerard.connolly@tudublin.ie. Funder: Bausch \& Lomb; Enterprise Ireland

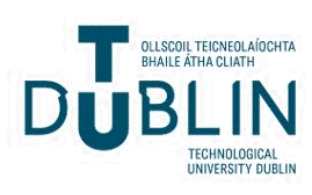




\section{Authors}

James Loughman, Peter Davison, Grainne Scanlon, and Veronica O'Dwyer

This conference paper is available at ARROW@TU Dublin: https://arrow.tudublin.ie/scschphycon/6 


\section{Spatial Vision}

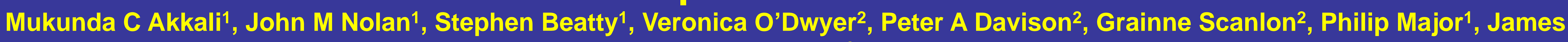
Loughman $^{2}$

\section{INTRODUCTION}

Macular pigment (MP), which is composed of three dietary carotenoids, lutein (L), zeaxanthin (Z) and meso-zeaxanthin (MZ), is predominantly located at the site of maximum visual acuity in the human retina. MP absorbs short wavelength light prior to photoreceptor stimulation. Filtering such defocused short wavelength (blue) light could enhance visual performance by reducing the effects of chromatic aberration and light scatter. ${ }^{1}$ This hypothesis, in relation to MP, remains unproven and poorly investigated to date.

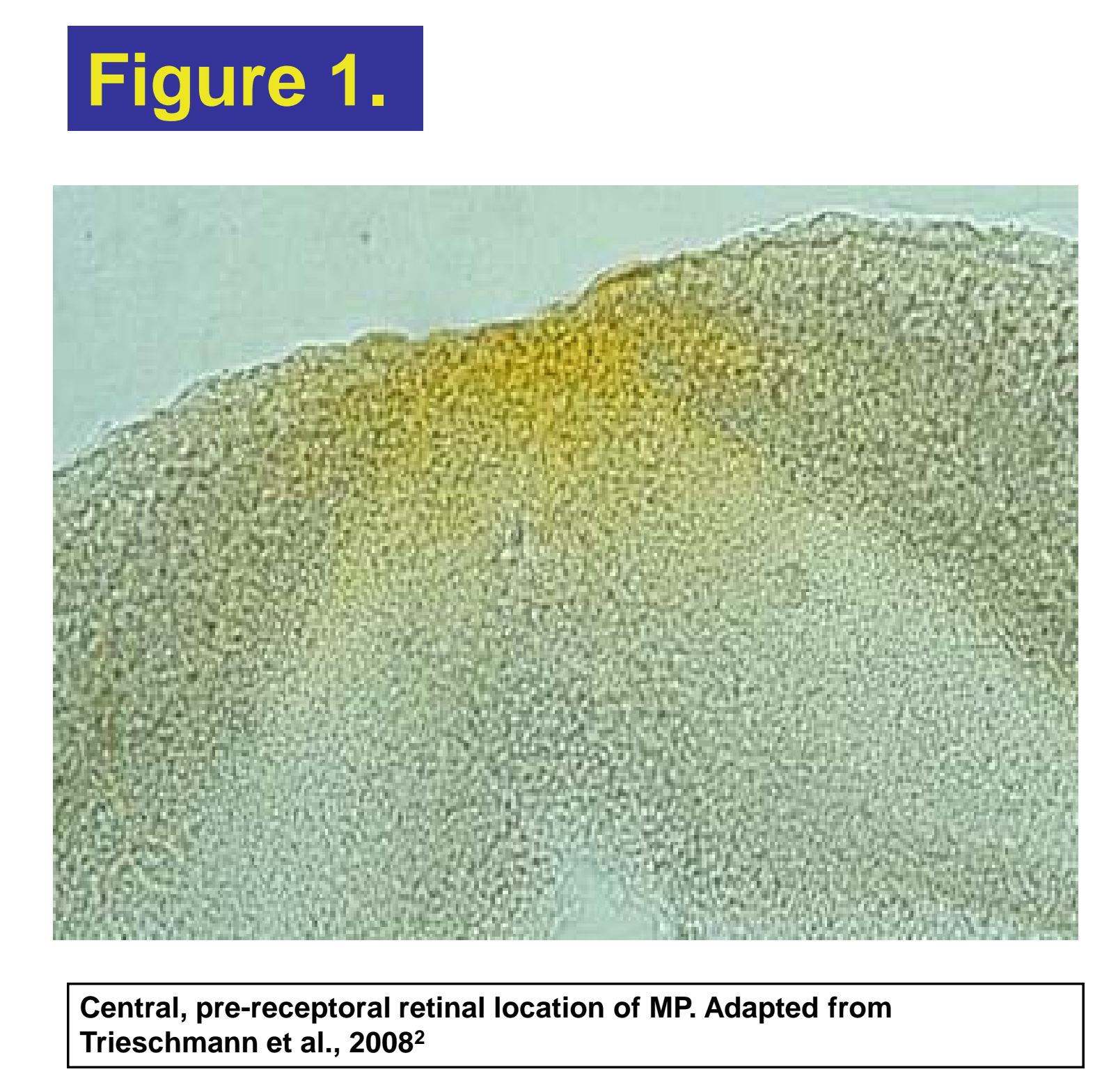

PURPOSE

The Collaborative Optical Macular Pigment ASsessment Study (COMPASS) is a double blind, placebo controlled and randomized clinical trial, designed to investigate whether MP optical density (MPOD)
influences spatial vision and visual comfort by means of selective shor influences spatial vision and visual comfort by means of selecti
wavelength light absorption prior to photoreceptor light capture.

\section{SUBJECTS and METHODS}

We recruited 142 young healthy subjects (mean \pm SD age $=28.85 \pm 6.37$ years). The spatial profile of MPOD was assessed by customized heterochromatic flicker photometry (cHFP), which has been shown to be a reliable and repeatable method of quantifying MPOD. ${ }^{3}$ Visual performance was assessed using visual acuity, mesopic and photopic contrast sensitivity, glare sensitivity and photostress recovery time measures. Each subject also completed a visual performance questionnaire, generating a performance index of the subject's perception of their functional vision in terms of colour, acuity, glare, light/dark adaptation and daily visual tasks.

\section{MPOD measurement}

MPOD measurements were obtained by cHFP (using the Macular Densitometer $\left.{ }^{\mathrm{TM}}\right)$ at five loci $\left(0.25^{\circ}, 0.50^{\circ}, 1^{\circ}, 1.75^{\circ}\right.$ and $3^{\circ}$ of retina eccentricity), with a reference point at $7^{\circ}$, to generate a complete spatial profile of MP.

\section{Best corrected visual acuity (BCVA)}

BCVA was assessed using a computer-generated LogMAR, high contrast chart, employing a SLOAN ETDRS letterset. A visual acuity rating (VAR) was computed to quantify precise acuity limits.
Contrast sensitivity function (CSF)

Mesopic $\left(3 \mathrm{~cd} / \mathrm{m}^{2}\right)$ and photopic $\left(100 \mathrm{~cd} / \mathrm{m}^{2}\right)$ CSF curves were plotted using spatial frequencies of 1 cycle per degree (cpd), $4.1 \mathrm{cpd}, 7.5 \mathrm{cpd}, 11.8 \mathrm{cpd}$ and $20.7 \mathrm{cpd}$. Gabor stimuli were displayed on a CRT monitor and sensitivities were determined using a linear staircase procedure.

\section{Glare sensitivity}

Mesopic $\left(3 \mathrm{~cd} / \mathrm{m}^{2}\right)$ and photopic $\left(85 \mathrm{~cd} / \mathrm{m}^{2}\right)$ contrast sensitivity was also tested under glare conditions using a sine grating functional acuity contras test, and a radial glare source. CSF curves were plotted using spatia frequencies of $1.5 \mathrm{cpd}, 3 \mathrm{cpd}, 6 \mathrm{cpd}, 12 \mathrm{cpd}$ and $18 \mathrm{cpd}$. Glare effects on the CSF were determined for medium (35 Lux) and high (128 Lux) glare intensities.

\section{Photostress Recovery Time (PRT)}

PRT was evaluated using a previously described macular automated photostress test ${ }^{4}$ using a Humphrey 745 visual field analyzer.

\section{RESULTS}

These results represent the baseline findings from COMPASS. Mean \pm SD MPOD obtained at peak $\left(0.25^{\circ}\right.$ eccentricity) was $0.48 \pm 0.19$. There was a statistically significant positive relationship between BCVA and MPOD at al retinal eccentricities $(r=0.236$ to $0.354, p<0.01)$ [Figures 2 and Figure 3 illustrate the relationship at $0.25^{\circ}$ and $0.50^{\circ}$ respectively].
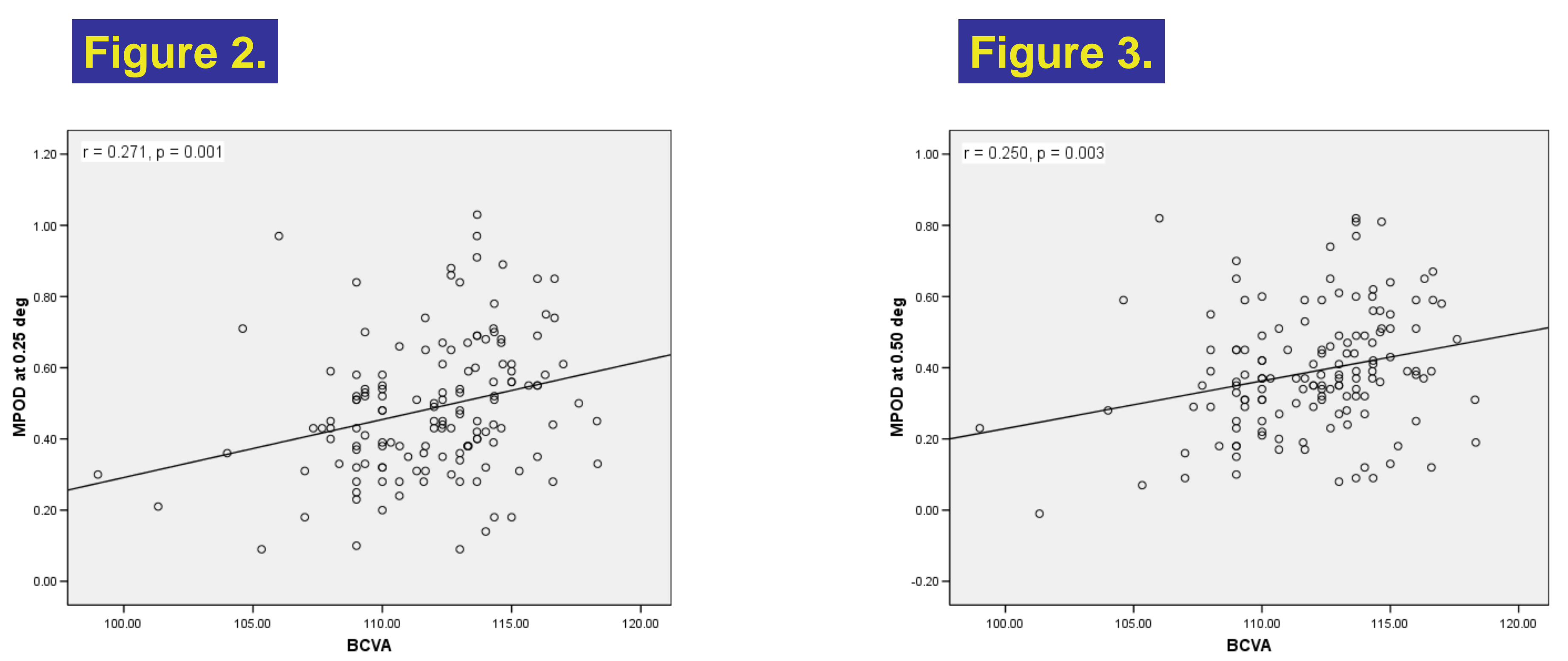

There was a statistically significant positive relationship between mesopic and photopic contrast sensitivities and MPOD, but confined to the central $0.50^{\circ}$ of retinal eccentricity (mesopic contrast sensitivity @ $7.5 \mathrm{cpd}, 11.8$ cpd and MPOD at $0.25^{\circ}, 0.50^{\circ}: r=0.171$ to $0.210, p<0.05$; photopic contrast sensitivity @ $1.0 \mathrm{cpd}, 7.5 \mathrm{cpd}, 11.8 \mathrm{cpd}$ and MPOD at $0.25^{\circ}$ $0.50^{\circ}: r=0.174$ to $0.197, p<0.05$; [Figures 4 and 5 illustrate the relationship between MPOD at $0.25^{\circ}$ and both mesopic and photopic contrast sensitivity at $7.5 \mathrm{cpd}$ respectively].
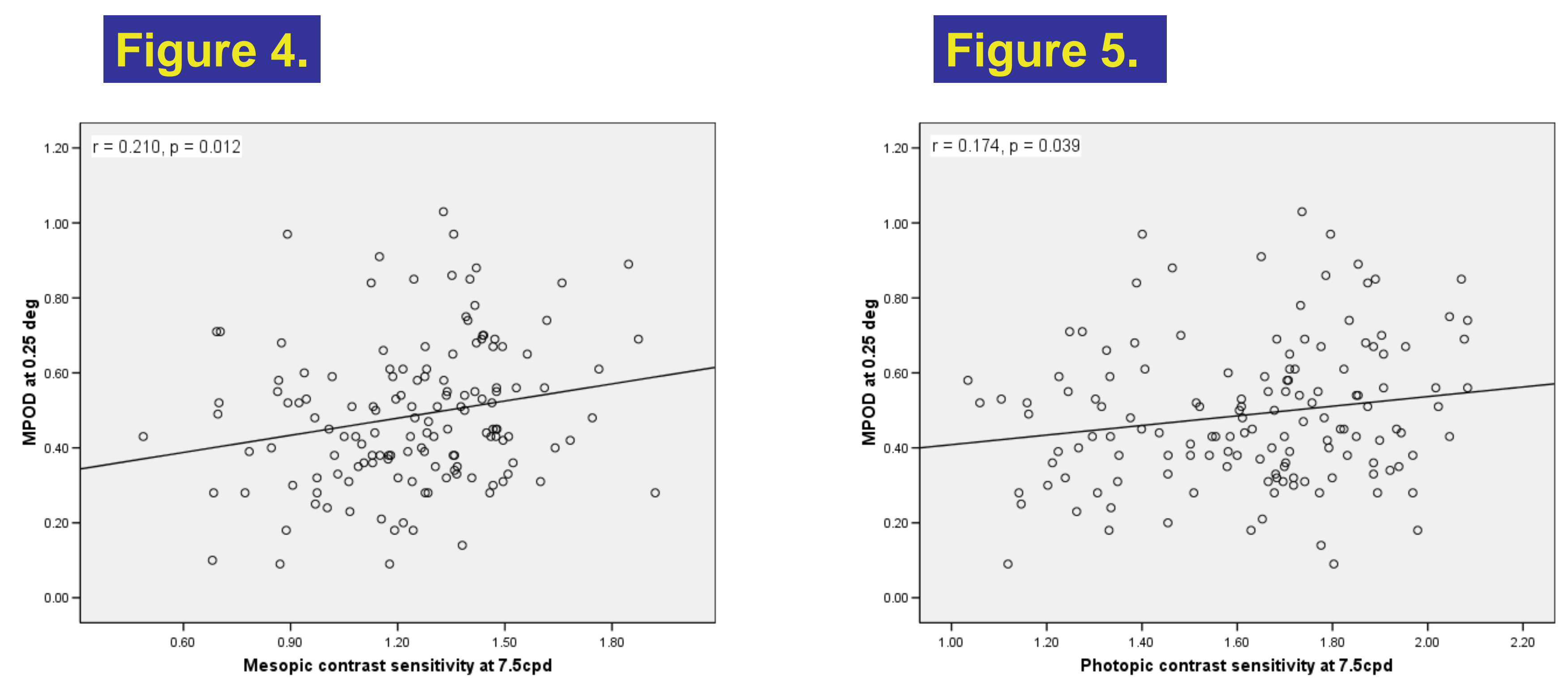

There was an inverse relationship between mesopic contrast sensitivity under glare conditions for all spatial frequencies and MPOD at all degrees of retinal eccentricity, but was not statistically significant ( $p$ > 0.05).

There was no statistically significant relationship observed between MPOD and any of the functional aspects of subjective visual function questionnaire $(r=-0.188$ to $0.148, p>0.05)$. There was also no statistically significant relationship observed between MPOD and PRT. $(r=0.002$ to $0.102, p>0.05)$

\section{CONCLUSION}

Given its short wavelength absorption characteristics and central, prereceptorial location [see Figure 1], MP exhibits ideal properties to optimize visual performance. Visual performance, as assessed by visual acuity and contrast sensitivity measures, does appear to be influenced by MPOD. Photostress recovery and visual performance under glare conditions however show no significant relationship with MPOD.

The lack of consistency among the results possibly reflects the inherent difficulty associated with efforts to clarify the role of MP with respect to visua performance using a cross sectional methodology. A placebo controlled, randomized MP supplementation clinical trial, has the capacity to more adequately address the critical research question.

\section{REFERENCES}

(1) Wooten BR, Hammond BR. Macular pigment: influences on visual acuity and visibility. Prog Ret Eye Res 2002 Mar;21(2):225-240.

(2) Trieschmann M, van Kuijk FJ, Alexander R et al. Macular pigment in the human retina: histological evaluation of localization and distribution. Eye 2008 January;22(1):132-7. (3) Kirby ML, Galea M, Loane E, Stack J, Beatty S, Nolan JM. Foveal Anatomic Associations with the Secondary Peak and the Slope of the Macular Pigment Spatial Profile. Invest Ophthalmol Vis Sci 2009 Mar;50(3):1383-1391 (4) Dhalla MS, Fantin A. Macular photostress testing: sensitivity and recovery with an
automated perimeter. Retina 2005 February;25(2):189-92.

Bausch\&Lomb $\quad$ ENTERPRISE
IRELAND

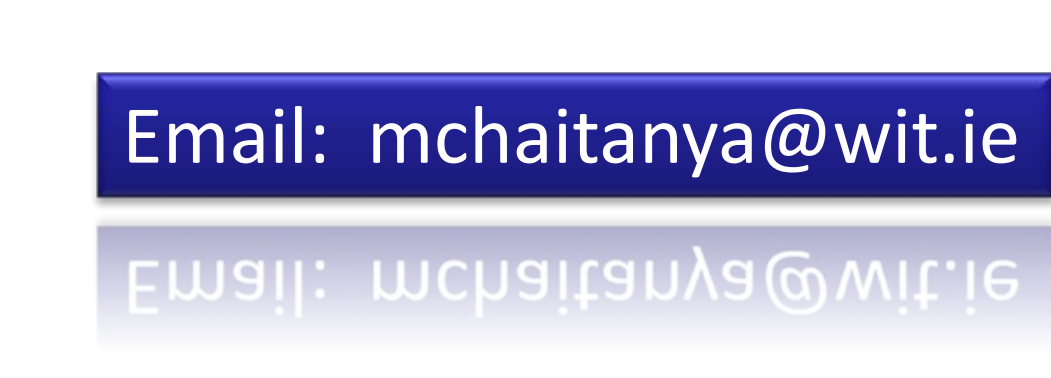

